\title{
Femoral Intertrochanteric Fracture and All-Cause Mortality Risk in Aged Osteoporosis Patients
}

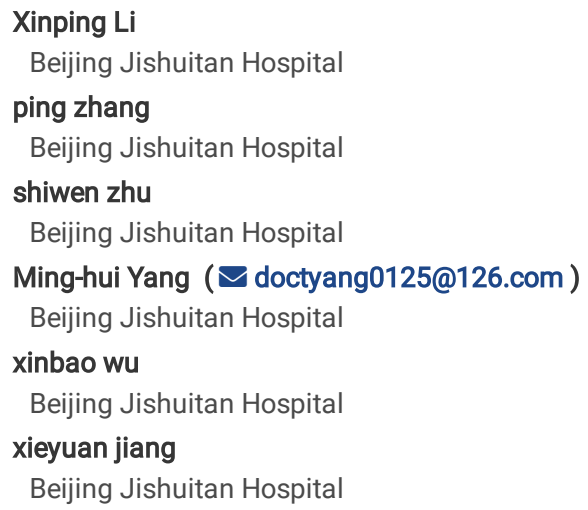




\section{Abstract}

Introduction冈Clinicians pay attention to the risk factors of all-cause mortality after hip fracture, and expect to make intervention and choice. With the progress of diagnosis and treatment mode and technology, the composition and influence degree of risk factors changed in some extent.

Materials and methods $\ T h i s$ is a single-center prospective cohort study based on the real world, under the co management of orthopedics and geriatrics, 363 patients aged $\geq 65$ years with femoral intertrochanteric fracture were enrolled and were followed up for 2-3 years; 52 patients were lost to follow up. Age, genders, body mass index (BMI), history of comorbidities, hip Bone Mineral Density (BMD), fracture history, 25(OH)D level, hemoglobin level, anti osteoporosis treatment were risk factors to be tested. Kaplan-Meier survival curves and multivariate Cox proportional hazards models were constructed to the analyzed impact of factors on all-cause mortality.

Results (1) Most of the dead patients were older, with more complications and without anti osteoporosis medication; gender, pre-fracture history, BMI, total hip $\mathrm{BMD}$, hemoglobin, 25(OH)D had no difference between the dead and the living patients. (2) Elderly patients with Intertrochanteric fracture can benefit from the early treatment of Zoledronic Acid ( $\leq 3$ days).

Conclusions: Under the co management of orthopedics and geriatrics, to Chinese patients with Femoral Intertrochanteric fracture, Doctors should pay more attention to their age and chronic diseases, and give anti osteoporosis treatment if allowed.

\section{Introduction}

Hip fracture is one of the main consequences of osteoporosis, with devastating results for the affected patients, including markedly increased subsequent fracture risk [1] and significant increased all-cause mortality [2]. Approximately $33 \%$ of men and $22 \%$ of women suffering a hip fracture will die within 1 year [34]. To patients older than 75 , Intertrochanteric fracture contributed more to the crude growth rate than femoral neck fracture [5]. Now, doctors believe that refracture [6] and all-cause mortality [7] can be reduced by early surgery [8], reduced bed rest and anti-osteoporosis treatment [6,9]. Especially in recent years, with the participation of Orthogeriatrics, the proposal of the concept of rapid rehabilitation, the increase in the use of anti osteoporosis drugs, and the improvement of medical care and patients' understanding of the disease, the in-hospital mortality and all-cause mortality of elderly hip fracture patients have been further reduced. It can also be seen from the repeated correction of Nottingham Hip Fracture Score (NHFS)[10-12].

In this context, this paper aims to explore the risk factors of all-cause mortality in patients with femoral intertrochanteric fracture under the co management of orthopedics and geriatrics.

\section{Patients And Methods}

\section{Study Population}

After the patient admitted at the emergency department a pelvic X-ray is made as soon as possible; after diagnosing a hip fracture, a geriatrician is consulted prior to surgery for each patient with a hip fracture. All the patients over 65 years will be admitted to the geriatric trauma unit within the orthopedic trauma department; and geriatrics and orthopedics were managed together throughout the hospitalization. The mean time from admission to surgery was 66.5 hours, $49.8 \%$ patients had surgery within 48 hours on admission. No surgery during weekends. Early mobilization after surgery with a physiotherapist was arranged at the first day from postoperative.

A total of 363 patients aged $\geq 65$ years with femoral intertrochanteric fracture were enrolled in this prospective cohort study, the patients were consecutively admitted from May 2015 to December 2017; 52 patients were lost to follow up, 311 patients were followed up for 2-3 years. The patients were aged from 65 to 99 years, with an average of $80.2 \pm 6.5$ years. There were 80 women and 231 men. There were $223(72.9 \%)$ patients with internal diseases and $69(22.5 \%)$ with three or more types of internal disease. The Charlson comorbidity index (CCl) was 0-6.

All patients were given osteoporosis health education, and had basic calcium and vitamin D3. 139 patients accepted Zoledronic Acid 5mg(Aclasta) less than 3 days after surgery; because the number of patients treated with anti osteoporosis drugs other than ZOL is very small, only single digits, so this study does not include these patients. No patients had a nonunion at the end of the follow-up.

\section{Inclusion and Exclusion Criteria}

The inclusion criteria in our study were: (i) patients admitted with new femoral intertrochanteric fracture ( $\leq 3$ weeks) and patients aged $\geq 65$ years; (ii)patients who received no anti-osteoporosis medication before, except calcium + vitamin D supplementations; (iii) only unilateral fracture; (iv) creatinine clearance rate was higher than $35 \mathrm{ml} / \mathrm{min}$ (Cockcroft-Gault formula).

Exclusion criteria were as follows: (i) pathological fractures caused by malignant tumors; (ii) patients with secondary osteoporosis; (iii) high-energy fractures and/or age below 65 years; (iv) patients who have received other anti-osteoporosis medications except for ZOL and basement therapy, such as teriparatide acetate, Denosumab, etc. after surgery;(v) patients with life expectancy less than 2 years, patients with tumor metastasis.

\section{Follow-up Method}

The physicians followed up the patients or the family members who lived with the patients by outpatient service and telephone in this study. Time was expressed in months; time to death was calculated from the date of surgery. The date of death or the last interview with the patients or the family members was used to determine the end of follow-up. 


\section{Risk Factors}

Age, genders, body mass index, history of comorbidities (using CCI), hip BMD (DXA), fracture history, 25(OH)D level, and hemoglobin level were determined at the admission date. The secondary fracture was recorded during follow-up. Confounders were included in the final model if they changed the beta coefficient of the association $>5 \%$.

\section{Statistical Analysis}

A summary of the data was presented as mean \pm standard deviation, and/or percentage. For comparisons of patient's age, BMl, and CCI between two groups, $\mathrm{t}$-tests were used. For comparisons of gender, patients with $\mathrm{CCl} \geq 3$, and pre-fracture and post-fracture numbers between two groups, $\chi 2$-tests were used.

Kaplan-Meier survival curves were constructed and stratified by gender, age, CCl, and dosing ZOL or not. The impact factors on all-cause mortality were analyzed in multivariate Cox proportional hazards models. Forward and backward stepwise models and the Akaike information criterion were used to determine the most parsimonious models. All statistical analyses were performed using SPSS IBM version 19.0 software. P<0.05 was considered statistically significant.

\section{Results}

\section{General information}

The general data of living and dead patients was compared. The results showed that most of the dead patients were older, with more complications. However, the previous history of fragile fracture, BMI, total hip BMD, HGB, 25OHD had no difference between the dead and the living patients. The data are shown in Table 1. The average age of men was $80.7 \pm 6.6$ years old and that of women was $80.1 \pm 6.4$ years old. There was no significant difference in age between genders $(\mathrm{p}=0.470)$. There were 4 males $(5.0 \%)$ over 90 years old and 14 females $(6.1 \%)$.

\section{All-Cause Mortality of Cumulative survival rate}

A total of 311 patients with fractures were followed with an average time of $23.5 \pm 5.0$ months; a total of 37 patients died during the follow-up period and the cumulative mortality after fracture was $10.8 \%$, annual mortality for fracture was $5.4 \%$. There were 13 men and 24 women among these 37 deaths and the annual mortality was $6.1 \%$ in the male patients and $4.1 \%$ in the female patients. Of 37 deaths, 4 occurred within hospital, 6 occurred within 3 months, 4 within 6 months, and 14 within 1 year after the fracture. The most common causes of mortality were cardiovascular events and pneumonia.

Kaplan-Meier survival curves analysis showed that all-cause mortality increased in more elderly patients $(P=0.019$, Figure1-A); but only had growing trend with $\mathrm{CCl} 3$ or bigger $(P=0.149$, Figure1-B), and showed no gender difference $(P=0.101$, Figure $1-C)$, and there was a correlation between using ZOL and the cumulative survival rate $(P=0.004$,Figure $1-D)$.

\section{Multivariate Cox Regression Analysis}

The multivariate Cox proportional hazards model was applied to estimate the effects of factors on cumulative survival rate. The factors evaluated in this model included age, gender, BMI, fracture history, hip BMD, hemoglobin, 25OHD, CCl and dosing ZOL. In this study, BMI, fracture history, hip BMD, hemoglobin, and $250 \mathrm{HD}$ were not associated with all-cause mortality.

In Intertrochanteric fracture patients, during a mean observation period of 23.5 months, age $(p=0.022), C C l(p=0.046)$, and early use of ZOL ( $p=0.005)$ were associated with all-cause mortality; gender ( $p=0.126)$ was not relevant (Table2). In Intertrochanteric fracture patients, the elderly over 85 years had a 1.87 -fold higher risk than the younger elderly, and those with a CCI index over 3 had a 1.63-fold higher risk of all-cause mortality than those with less than 3 . In Intertrochanteric fracture patients, the early postoperative use of ZOL reduced the risk of all-cause mortality by $67 \%$.

\section{Discussion}

Hip fracture, as a common type of fragility fracture, has attracted attention because of its high perioperative risk and excess standardized mortality rate and re-fracture risk even after fracture surgery. At present, the recognized risk factors of hip fracture death include old age, male gender, place of residence, chronic disease, fracture type, anti-osteoporosis medicine et al[13-15]. While, with the co management of orthopedics and geriatrics, our all-cause mortality decreased significantly, 1-year mortality rate was $4.5 \%$ compare with $17.47 \%$, which was from a systematic analysis data after femoral intertrochanteric fracture between the years 2000 and 2018 in Mainland China [16]. Therefore, this article explored whether the risk factors of all-cause mortality changed under this model.

In recent years, many guidelines and expert consensus recommend that the multi department cooperative treatment group should be established in the treatment of hip fracture in elderly patients to improve perioperative safety, and operate as soon as possible (within $48 \mathrm{~h}$ ), and then accelerate rehabilitation under the guidance of rehabilitation doctors [17-19]. In the process of multi department collaborative treatment, the cooperation between orthopedics and geriatrics is very important. Grigoryan et al. [20] summarized 18 studies through meta-analysis and found that the cooperative treatment of elderly hip fractures by orthopedics doctors and geriatricians can shorten the length of hospital stay and reduce the in-hospital mortality and long-term mortality. It is a more efficient way to establish a special ward and adopt the co management mode between orthopedics and geriatrics (or internal medicine). Biber et al. [21] pointed out that the establishment of elderly fracture co management ward can shorten the preoperative waiting time and hospitalization time of elderly patients with femoral neck fracture. Through a prospective randomized controlled study, Prestmo et al. [22] found that the establishment of a special elderly hip fracture ward could improve the treatment results compared with the conventional orthopedic treatment mode. 
Under the co management mode of orthopedics and geriatrics, from our data, risk factors of all-cause mortality were older age, CCl and early use of ZOL; they were consistent with previous studies [13,15,23-24]. While male gender was not risk factor. It is speculated that different data have different gender and age distribution; it is also possible that the number of data in this paper is still insufficient and cannot show the difference. To the dosing of ZOL, we summarized different studies about all-cause mortality after bisphosphonates treatment in patients with hip fracture (Table3), from the hazard ratios, it seems China hip fracture population had better effects. The influence of ethnicity is huge. Such as, Chinese people are prone to atypical fracture after continuous BPs [25-27].

Hip fracture is the peak period of osteoporosis. It is very important to bring fragile hip fracture patients into the prevention and treatment program of osteoporosis. The difference between using ZOL to patients who are healing after fracture and to patients who have healed after fracture and patients with osteoporosis is that patients who suffering fracture are in the period of rich callus formation, and their bone metabolism is more active than those who not; therefore, after using ZOL during fracture healing, patients will retain more ZOL in the bone, which can play a more effective and longer anti-osteoporosis effect.

For the mechanism displayed, bisphosphonates (BPs) binds to hydroxyapatite crystals in bone, especially at sites with high bone turnover [28], which means BPs bind strongly at sites of new mineral deposition, also bind well to resorption sites. And more BPs is taken up by trabecular bone than cortical bone, for a higher rate of turnover and greater surface area available in trabecular bone [29]. BPs released from bone may undergo re-uptake onto bone surfaces, so they can be detected in urine for years after treatment discontinuation [30-31].

This mechanism suggests that the researchers should treat fracture and osteoporosis differently when it comes to the therapeutic effect of BPs. For the drug will leave more in the bone of fracture patients, will play a longer role, and maybe play different roles under different stress states. Therefore, the timing of using BPs after hip fracture surgery is very critical. Theoretically, it should be used within the callus formation period to achieve this effect. But we have no data to support this speculation.

The feature of this study was that ZOL is used within 3 days after surgery, which is early; for most of the published studies on the use of BPs after hip fracture have been used for 2-4 weeks or later. On the other hand, it verified that the early use of ZOL did not bring more adverse. Another feature of the study was that ZOL was used only once during the observation period of 2-3 years, due to the less attention paid to osteoporosis treatment by patients and their families and the inconvenient activities of patients. For ZOL effects on BMD and fracture risk persist for at least two years [32-34], it makes ZOL a more attractive proposition.

Determination of risk factors supports doctors to identify patients who were at high risk for mortality and enables accurate preoperative risk assessment. A known high risk for mortality can support appropriate informed consent (patient and family), timing of surgery, and enable possibilities for intervention with respect to perioperative management. Clinically, we should pay attention to the elderly patients with femoral intertrochanteric fracture complicated with a variety of basic medical diseases, and give anti osteoporosis treatment if allowed.

\section{Limitations}

There are still some deficiencies in our research. 1. It is real-world research, as ZOL has a clear benefit for patients with osteoporosis, it is not possible to perform double blind study; 2 . Many follow-up visits are telephone follow-up, so there are subjective factors.

\section{Declarations}

Ethics approval and consent to participate: The Ethics Board of Beijing Jishuitan Hospital approved the study with the approval number of $201907-09$.

Consent for publication: All authors consent for publication

Availability of data and materials: Not applicable

Competing interests: The authors have no conflicts of interest to declare.

Funding: Beijing Municipal Administration of Hospitals Incubating Program, Code: PX 2019015; Beijing Municipal Health Committee Scientific Research Project, Code: Beijing 19-17囚Beijing Hospitals Authority Youth Program, Code: QML20170401.

Authors' contributions: Author Xin-ping Li designed the study and prepared the first draft of the paper. Ming-hui Yang and Ping Zhang contributions to acquisition and interpretation of data. Authors Shi-wen Zhu, Xin-bao Wu, and Xie-yuan Jiang contributed to the design of the work and the interpretation of data. All authors revised the paper critically for intellectual content and approved the final version. All authors agree to be accountable for the work and to ensure that any questions relating to the accuracy and integrity of the paper are investigated and properly resolved.

Acknowledgements: Thank all colleagues in the elderly hip fracture ward for their hard work.

\section{References}

1. Gibson-Smith D, Klop C, Elders PJ, et al. The risk of major and any (nonhip) fragility fracture after hip fracture in the United Kingdom: 20002010.Osteoporos Int 2014;25:2555-2563.

2. Nazrun AS, Tzar MN, Mokhtar SA, Mohamed IN. A systematic review of the outcomes of osteoporotic fracture patients after hospital discharge: Morbidity, subsequent fractures, and mortality. Ther Clin Risk Manag 2014;10:937-948.

3. Brauer CA, Coca-Perraillon M, Cutler DM, Rosen AB. Incidence and mortality of hip fractures in the United States. JAMA 2009;302:1573-1579.

Page $4 / 8$ 
4. Klop C, Welsing PM, Cooper C, et al. Mortality in British hip fracture patients,2000-2010: A population-based retrospective cohort study. Bone 2014;66:171177.

5. Gong X F , Li X P , Zhang L X , et al. Current status and distribution of hip fractures among older adults in China[J]. Osteoporosis International, 2021(1-2).

6. Lee SY, Jung SH, Lee SU, et al. Can bisphosphonates prevent recurrent fragility fractures? A systematic review and meta-analysis of randomized controlled trials. J Am Med Dir Assoc 2018;19:384-390.e1.

7. Abtahi S, Burden A M , Geusens P, et al. The Association of Oral Bisphosphonate Use With Mortality Risk Following a Major Osteoporotic Fracture in the United Kingdom: Population-Based Cohort Study[J]. Am Med Dir Assoc. 2020 Jun;21(6):811-816.

8. Wenjing, Li, Minghui. Fragility Fracture Network (FFN)-China successfully held forum to support FFN Global Call to Action to improve the care of people with fragility fractures[J]. Aging Medicine, 2018;1:280-281.

9. Akesson K,Marsh D,Mitchell PJ,et al. Capture the Fracture: a best practice framework and global campaign to break the fragility fracture cycle[J]. Osteoporos Int,2013,24(8):2135-2152.

10. Maxwell MJ, Moran CG, Moppett IK. Development and validation of a preoperative scoring system to predict 30 day mortality in patients undergoing hip fracture surgery. Br J Anaesth 2008;101:511e517.

11. Marufu TC, White SM, Griffiths R, et al. Prediction of 30-day mortality after hip fracture surgery by the Nottingham Hip Fracture Score and the Surgical Outcome Risk Tool. Anaesthesia 2016;71:515e521.

12. Moppett IK, Parker M, Griffiths R, et al. Nottingham Hip Fracture Score: Longitudinal and multi-centre assessment. Br J Anaesth 2012;109:546e550.

13. Chang-Bi Wang, Chien-Fu Jeff Lin, Wen-Miin Liang, et al. Excess mortality after hip fracture among the elderly in Taiwan: a nationwide population-based cohort study.Bone 2013 Sep;56(1):147-53

14. Pei-en Wang, Yi-hong Li, Hua-feng Zhuang, et al. Anti Osteoporosis Medications Associated with Decreased Mortality after Hip Fracture[J]. Orthopaedic Surgery, 2019, 11(5).

15. Thao Phuong Ho-Le, Thach S Tran, Dana Bliuc, et al. Epidemiological transition to mortality and refracture following an initial fracture. eLife 2021 Feb $09 ; 10$

16. Zhiyong Cui, Hui Feng, Xiangyu Meng, et al. Age-specific 1-year mortality rates after hip fracture based on the populations in mainland China between the years 2000 and 2018: a systematic analysis.Archives of osteoporosis 201905 25;14(1):55

17. Brox W T, Roberts K C, Taksali S, et al. The American Academy of Orthopaedic Surgeons Evidence-Based Guideline on Management of Hip Fractures in the Elderly[J]. Journal of Bone \& Joint Surgery-american Volume, 2015, 97(14):1196-1199.

18. Sign S. Management of hip fracture in older people. (SIGN Guideline No 111)[J]. geriatrics, 2009.

19. Chinese Geriatrics Society Bone and Joint Association Orthopaedic Trauma Committee .Experts' concensus on diagnosis and management of geriatric hip fractures(2017)[J] C.hin J Orthop Trauma,2017,19 (11):921-927

20. Grigoryan K V , Javedan H , Rudolph J L. Orthogeriatric care models and outcomes in hip fracture patients: a systematic review and meta-analysis.[J]. Journal of Orthopaedic Trauma, 2014, 28(3):e49.

21. Biber R, Singler K, Curschmann-Horter M , et al. Implementation of a co-managed Geriatric Fracture Center reduces hospital stay and time-to-operation in elderly femoral neck fracture patients[J]. Archives of Orthopaedic\&Trauma Surgery, 2013.

22. Anders Prestmo, Gunhild Hagen, Olav Sletvold, et al. Comprehensive geriatric care for patients with hip fractures: a prospective, randomised, controlled trial[J]. Lancet, 2015, 385(9978):1623-1633.

23. Dana Bliuc, Nguyen D Nguyen, Vivienne E Milch, et al. Mortality risk associated with low-trauma osteoporotic fracture and subsequent fracture in men and women.JAMA 2009 Feb 04;301(5):513-21

24. Pia Nimann Kannegaard, Susanne van der Mark, Pia Eiken, Bo Abrahamsen; Excess mortality in men compared with women following a hip fracture. National analysis of comedications, comorbidity and survival. Age and ageing 2010 Mar;39(2):203-9

25. [25] Koh JH囚Myong JP囚Yoo J囚et al. Predisposing factors associated with atypical femur fracture among postmenopausal Korean women receiving bisphosphonate therapy: 8years' experience in a single center[J].0steoporos Int, 2017,28(11):3251-3259.

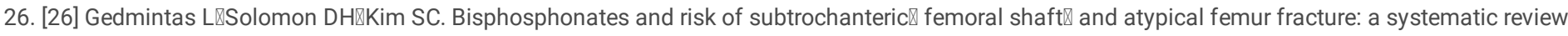
and meta analysis[J]. J Bone Miner Res,2013, 28(8):1729-1737.

27. [27] Lo JC. Huj RLهGrimsrud CD囚et al. The association of race/ ethnicity and risk of atypical femur fracture among older women receiving oral bisphosphonate therapy[J].Bone,2016,85: 142-147.

28. [28] Fleisch H, Russell RG, Francis MD. Diphosphonates inhibit hydroxy- apatite dissolution in vitro and bone resorption in tissue culture and in vivo. Science. 1969;165(3899):1262-1264.

29. [29] Weiss HM, Pfaar U, Schweitzer A, Wiegand H, Skerjanec A, Schran H. Biodistribution and plasma protein binding of zoledronic acid. Drug Metabol Dispos. 2008;36(10):2043-2049.

30. [30] Khan SA, Kanis JA, Vasikaran S, et al. Elimination and biochemical responses to intravenous alendronate in postmenopausal osteoporosis. J Bone Miner Res. 1997;12(10):1700-1707.

31. [31] Papapoulos SE, Cremers SC. Prolonged bisphosphonate release after treatment in children. N Engl J Med. 2007;356(10):1075-1076.

32. [32] Andrew G, Bolland M J , Diana W , et al. The antiresorptive effects of a single dose of zoledronate persist for two years: a randomized, placebocontrolled trial in osteopenic postmenopausal women.[J]. Journal of Clinical Endocrinology \& Metabolism, 2009(2):538-544.

33. [33] Reid IR, Horne AM, Mihov B, et al. Fracture prevention with zoledronate in older women with osteopenia. N Engl J Med 2018;379: 2407-2416.

Page 5/8 
34. [34] Reid IR, Black DM, Eastell R, et al. Reduction in the risk of clinical fractures after a single dose of zoledronic Acid 5 milligrams. The Journal of clinical endocrinology and metabolism 2013;98: 557-63.

35. Lyles KW, Colón-Emeric CS, Magaziner JS, et al. Zoledronic acid and clinical fractures and mortality after hip fracture. N Engl J Med 2007;357:1799-1809.

36. Eriksen E F , Lyles K W , Cathleen S Colón-Emeric, et al. Antifracture efficacy and reduction of mortality in relation to timing of the first dose of zoledronic acid after hip fracture.[J]. Journal of Bone \& Mineral Research, 2009, 24(7):1308-1313.

37. Bergman J , Nordstrm A , Hommel A, et al. Bisphosphonates and mortality: confounding in observational studies?[J]. Osteoporos Int. 2019 Oct;30(10):1973-1982.

38. W Brozek, B Reichardt, J Zwerina , et al. Antiresorptive therapy and risk of mortality and refracture in osteoporosis-related hip fracture: a nationwide study[J]. Osteoporosis International, 2016, 27(1):387-396.

39. Bondo L , Eiken $P$, Abrahamsen $B$. Analysis of the association between bisphosphonate treatment survival in Danish hip fracture patients a nationwide register based open cohort study[J]. Osteoporosis International, 2013, 24(1):245-252.

40. Axelsson K F , Wallander M , Johansson H, et al. Hip fracture risk and safety with alendronate treatment in the oldest-old[J]. J Intern Med. 2017 Dec;282(6):546-559.

41. Beaupre L A, Morrish D W , Hanley D A, et al. Oral bisphosphonates are associated with reduced mortality after hip fracture[J]. Osteoporosis International, 2011, 22(3):983-991.

42. Van G T A C M, Dana B, Geusens P P M, et al. Reduced mortality and subsequent fracture risk associated with oral bisphosphonate recommendation in a fracture liaison service setting: A prospective cohort study[J]. Plos One, 2018, 13(6):e0198006.

\section{Tables}

Table 1 General condition of the Femoral Intertrochanteric fracture patients

\begin{tabular}{|c|c|c|c|c|c|c|c|c|c|c|}
\hline & Case & Age & Pre-fracture & Re-fracture & BMI & Hip-BMD & HGB & $250 \mathrm{HD}$ & $\mathrm{CCl} \geq 3$ & Zoledronic acid \\
\hline & $\mathrm{M} / \mathrm{F}$ & & $\mathrm{M} / \mathrm{F}$ & $\mathrm{M} / \mathrm{F}$ & $\mathrm{g} / \mathrm{cm}^{2}$ & $\mathrm{~g} / \mathrm{cm}^{2}$ & $g / l$ & $\mathrm{ng} / \mathrm{ml}$ & $n(\%)$ & $\mathrm{n}(\%)$ \\
\hline Alive & $274(67 / 207)$ & $79.8 \pm 6.4$ & $13 / 55$ & $5 / 19$ & $23.5 \pm 3.6$ & $0.666 \pm 0.125$ & $113.7 \pm 17.0$ & $12.5 \pm 8.2$ & $58(21.2)$ & $128(46.7)$ \\
\hline Death & $37(13 / 24)$ & $83.4 \pm 6.0$ & $3 / 2$ & $0 / 1$ & $22.2 \pm 4.0$ & $0.647 \pm 0.162$ & $108.2 \pm 20.5$ & $11.0 \pm 7.3$ & 12(32.4) & 11(29.7) \\
\hline Total & $311(80 / 231)$ & $80.2 \pm 6.5$ & $16 / 57$ & $5 / 20$ & $23.4 \pm 3.6$ & $0.664 \pm 0.130$ & $113.0 \pm 17.4$ & $12.3 \pm 8.1$ & $70(22.5)$ & $139(44.7)$ \\
\hline p-value* & 0.253 & 0.001 & 0.126 & 0.759 & 0.042 & 0.448 & 0.087 & 0.333 & 0.035 & 0.140 \\
\hline
\end{tabular}

Abbreviations: M, male; F, female; BMI, body mass index; BMD, bone mineral density; $\mathrm{HGB}$, hemoglobin; $\mathrm{CCl}$, Charlson comorbidity index; $\star \otimes t$ the compare between alive and death;

Table 2 Multivariate Cox proportional Analysis of Risk Factors for Mortality in hip fracture patients

\begin{tabular}{llll} 
Type & Variable & $\mathrm{HR}(95 \% \mathrm{Cl})$ & P Value \\
\hline Intertrochanteric fracture & Gender, male/female & - & 0.126 \\
\cline { 2 - 3 } & Age, $\geq 85 / 75-85 /<75 y e a r s$ & $1.87(1.10-3.19)$ & 0.022 \\
\hline & $\mathrm{CCl}, \geq 3 / 1-2 / 0$ & $1.63(1.01-2.63)$ & 0.046 \\
\hline ZOL, use/none & $0.33(0.16-0.71)$ & 0.005
\end{tabular}

Abbreviations: $\mathrm{Cl}$, confidence interval; HR, hazard ration; $\mathrm{CCl}$, Charlson comorbidity index; ZOL ,Zoledronic acid; Blank cells indicate variables were not significant in the multivariate Cox proportional hazards models.

Table 3 Simple summary of different studies on improving all-cause mortality after Bisphosphonates treatment in patients with hip fractures 


\begin{tabular}{|c|c|c|c|c|c|c|c|c|c|c|}
\hline Research & Anti-OP drug & Use time & Frequency & Fracture type & $\begin{array}{l}\text { Race or } \\
\text { region }\end{array}$ & $\begin{array}{l}\text { Research } \\
\text { type }\end{array}$ & $\begin{array}{l}\text { Treated } \\
\text { cases } \\
\mathrm{N}\end{array}$ & Age & $\begin{array}{l}\text { Mean } \\
\text { follow- } \\
\text { up } \\
\text { time } \\
\text { (M) }\end{array}$ & $\mathrm{HR}(95 \% \mathrm{Cl})$ \\
\hline 2007Lyles[35] & ZOL & $\begin{array}{l}\leq 90 \text { days } \\
\text { after } \\
\text { surgical }\end{array}$ & yearly & Hip fracture & no Asia & $\begin{array}{l}\text { randomized, } \\
\text { double-blind, } \\
\text { placebo- } \\
\text { controlled } \\
\text { trial }\end{array}$ & 1065 & $\geq 50$ & 22.8 & $0.72(0.56,0$. \\
\hline 2009Eriksen[36] & ZOL & $\begin{array}{l}\leq 2 \text { wk } \\
\text { after } \\
\text { surgical }\end{array}$ & yearly & Hip fracture & no Asia & $\begin{array}{l}\text { randomized, } \\
\text { double-blind, } \\
\text { placebo- } \\
\text { controlled } \\
\text { trial }\end{array}$ & 56 & $\geq 50$ & 22.8 & - \\
\hline 2019Bergman[37] & ZOL & - & - & Hip fracture & Sweden & $\begin{array}{l}\text { retrospective } \\
\text { cohort study }\end{array}$ & 161 & $\geq 50$ & 33.6 & $1.51(1.00,2$. \\
\hline 2019Wang[14] & ZOL & $\begin{array}{l}\leq 2 \text { weeks } \\
\text { after } \\
\text { admission }\end{array}$ & - & Hip fracture & China & $\begin{array}{l}\text { retrospective } \\
\text { study }\end{array}$ & 80 & $\geq 50$ & 28.5 & $0.36(0.19,0$. \\
\hline 2015Brozek[38] & $\begin{array}{l}\text { All BP and } \\
\text { Denosumab }\end{array}$ & $\leq 1$ year & - & Hip fracture & Austria & $\begin{array}{l}\text { retrospective } \\
\text { nationwide } \\
\text { cohort study }\end{array}$ & 2166 & $\geq 50$ & 36 & $0.48(0.42,0$ \\
\hline 2019Bergman[37] & Alendronate & - & - & Hip fracture & Sweden & $\begin{array}{l}\text { retrospective } \\
\text { cohort study }\end{array}$ & 4689 & $\geq 50$ & 33.6 & $0.82(0.76,0$. \\
\hline 2012Bondo[39] & Oral BP & $\begin{array}{l}5 \text { month } \\
\text { after } \\
\text { fracture }\end{array}$ & $\begin{array}{l}>\text { two } \\
\text { packs }\end{array}$ & Hip fracture & Danish & $\begin{array}{l}\text { nationwide } \\
\text { register- } \\
\text { based open } \\
\text { cohort study }\end{array}$ & 1096 & $\geq 55$ & 45.6 & $0.73(0.61,0$ \\
\hline 2017Axelsson[40] & Alendronate & - & $\begin{array}{l}\geq 3 \\
\text { months }\end{array}$ & Hip fracture & Sweden & $\begin{array}{l}\text { prospective } \\
\text { observational } \\
\text { register- } \\
\text { based study }\end{array}$ & 1961 & $\geq 80$ & 19.2 & $\begin{array}{l}0.88 \\
(0.82,0.95)\end{array}$ \\
\hline 2010Beaupre[41] & Oral BP & $\begin{array}{l}1 \text { and } 2 \\
\text { years }\end{array}$ & $\begin{array}{l}64 \% \\
\text { yearly }\end{array}$ & Hip fracture & Canada & $\begin{array}{l}\text { randomized } \\
\text { controlled } \\
\text { trial }\end{array}$ & 101 & $>50$ & 36 & $0.92(0.88,0$ \\
\hline 2018Van[42] & Oral BP & $\begin{array}{l}\text { 2weeks } \\
\text { later }\end{array}$ & $\begin{array}{l}\text { continued } \\
5 \text { years }\end{array}$ & $\begin{array}{l}\text { clinical } \\
\text { fracture }(21.7 \% \\
\text { for hip fracture) }\end{array}$ & Scotland & $\begin{array}{l}\text { prospective } \\
\text { cohort study }\end{array}$ & 2534 & $\geq 50$ & 44.9 & $0.79(0.64,0$. \\
\hline this study & ZOL & $\begin{array}{l}\leq 3 \text { days } \\
\text { after } \\
\text { surgical }\end{array}$ & once & $\begin{array}{l}\text { Intertrochanteric } \\
\text { fracture }\end{array}$ & China & $\begin{array}{l}\text { prospective } \\
\text { cohort study }\end{array}$ & 139 & $\geq 65$ & 23.5 & $0.33(0.16-0$. \\
\hline
\end{tabular}

Abbreviations: OP, osteoporosis; HR, hazard ration; Cl, confidence interval; ZOL , Zoledronic acid; BP, Bisphosphonates; - indicate variables were not significant in the multivariate Cox proportional hazards models.

\section{Figures}




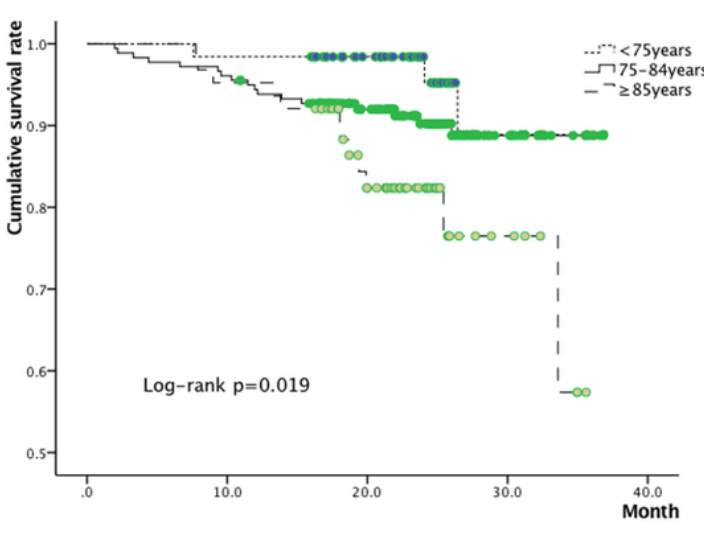

A

Cumulative survival of patients with Intertrochanteric fractures by age

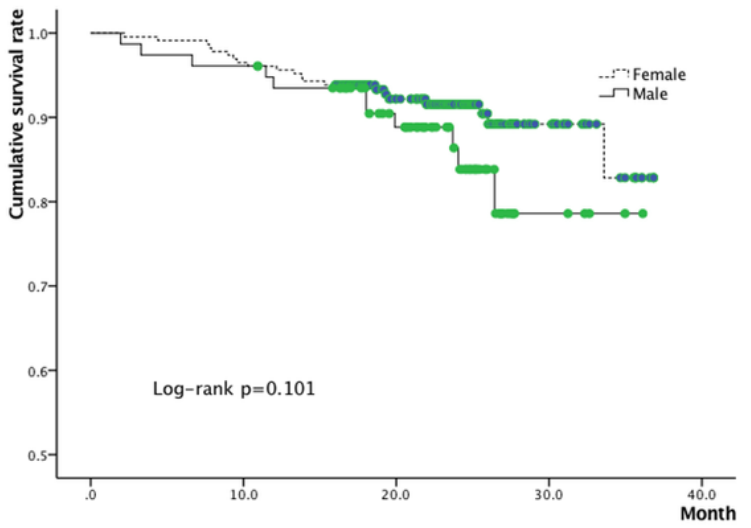

C Cumulative survival of patients with Intertrochanteric fractures by gender

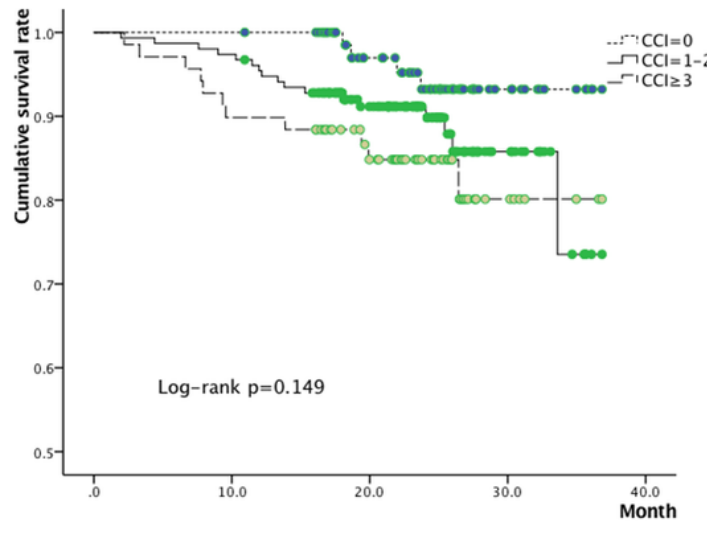

B

Cumulative survival of patients with Intertrochanteric fractures by Charlson Comorbidity Index (CCI)

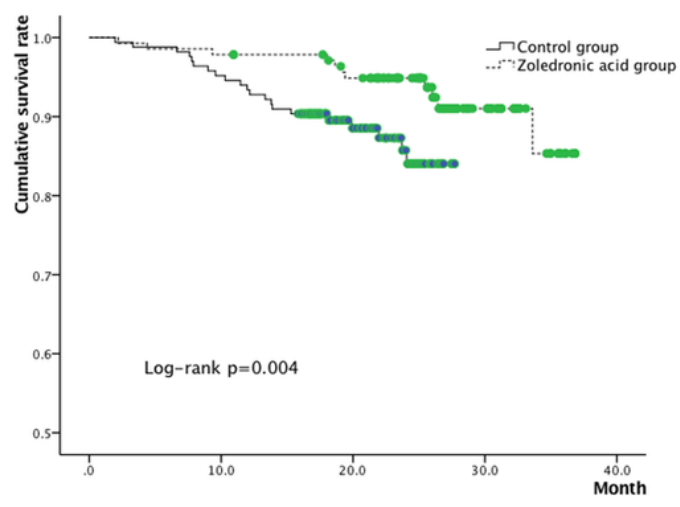

$\mathrm{D}$

\section{Figure 1}

Cumulative survival of Intertrochanteric fracture patients by gender (A), age(B), Charlson Comorbidity Index(C) and dosing Zoledronic acid or not(D). 